\title{
Technological and Economic Aspects of Wave Energy Harvesting
}

\author{
Rahul Basu \\ Professor, Mechanical Engineering, Adarsha Institute of Technology, Kundana, Bangalore 562110, India, E-mail: \\ raulbasu@gmail.com
}

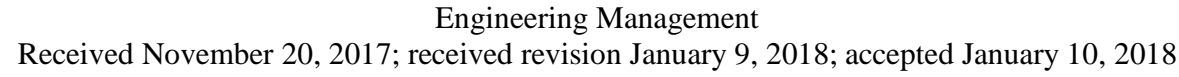

Available online January 11, 2018

\begin{abstract}
The geographical regions contiguous to the Indian Ocean, Bay of Bengal and the Arabian Sea are prone to natural disasters and poor electric supply especially in rural and hard to reach coastal regions. Utilization of ocean resources for power generation such as tidal, thermal solar and wind for energy need to be incorporated in a broad framework for the region. Development of ocean-based energy systems can be integrated with early warning networks linked by satellite which can give a few hours to days warning to help mitigate the severity of natural disasters on human life. Ocean-based electricity extraction has; however, remained elusive for various reasons. Interest in these systems resumed after the oil crisis of the 1970's, but was uncoordinated. Extraction of ocean energy from the kinetic energy of waves and ocean currents depends on various mechanical devices with variable efficiencies. Apart from the efficiency, one must match the output phase of the feeder waveforms with that of the electrical grid. Also, the wavelengths of the typical wave are of the order of a few meters, the interception of which requires large devices. The mechanical efficiency of the turbine extraction system is further limited by the flow momentum considerations. Some applications and their implementation are looked at, specifically with reference to the difficulties of implementation in the region, and other factors like economic efficiency (rate of returns) in place of mechanical efficiency). Individual wave energy harvesters are thus bound to suffer from inefficiencies and it may be beneficial to use wave farm configurations from the point of view of the randomness of wave motion, the large wavelengths, and the added advantage of averaging fluctuations from large numbers of generators.
\end{abstract}

Keywords: Renewable energy, wave power, tidal energy, early warning network.

\section{Introduction}

Solar Energy can be harvested from the ocean through ocean currents. Ocean currents being solar and wind generated near the equator are classifiable into marine and tidal currents. Marine currents flow in one direction and are relatively constant. Tidal currents, however, are found near the shoreline due to gravitational forces of the moon. Some important currents include the Gulf Stream, Florida Straits Current, and the California Current. The wind and thermal energy get stored in the ocean as currents and surface waves. Wave heights and widths change during the year. Kinetic energy is proportional to the cube of velocity and density. Ocean energy is comparable to wind energy because the two are forms of hydrodynamic and fluid flows. Ocean currents are slower than wind speeds, however, as sea water is 832 times denser than air. Also, ocean currents can be predicted years in advance since these depend on the sun and the moon. Worldwide, ocean currents of more than five knots or $2.5 \mathrm{~m} / \mathrm{s}(1 \mathrm{knot}=0.50 \mathrm{~m} / \mathrm{s})$ exist. Ocean current energy has been estimated greater than $5,000 \mathrm{GW}$, with power densities of up to $15 \mathrm{~kW} / \mathrm{m}^{2}$, USDOI (2006). Another estimate projects 2000 TWh/year, Clement (2002).

Ocean currents of 4-5 knots occur along the E. African coast and have been studied extensively by Lutjeharms (1981) and Tomczak (2003). The feasibility of using ocean currents off Hawaii was undertaken by the DBEDT (2002). In the 1970's there were numbers of studies on wave energy including Mauritius (Walton, 1978) which were initiated after the oil crisis. Studies have also been done by Szabo (2009) for the Black Sea area.

Extractable power from the flowing fluid varies with kinetic energy as

$$
\mathrm{P} / \mathrm{A}=1 / 2 \rho \mathrm{V} 3
$$

Where A (in square meters), $\rho$, fluid density (in kilograms per cubic meter; $1,000 \mathrm{~kg} / \mathrm{m} 3$ for freshwater and $1,025 \mathrm{~kg} / \mathrm{m} 3$ for seawater), $\mathrm{V}$ being flow velocity (meters per second). The velocity is the main factor, also in wind power, since it appears as a cube power. Wave energy also goes as the square of the amplitude and period of the wave. Hence, long periods and large 
amplitudes are attractive. Various wave energy generators have been used, the Indian experiments have been with oscillating water columns types (150 KWh) at Vizingham fisheries harbor near Trivandrum (Kerala) in 1991, Khan (2009). Successful trials led to improved capacity turbine generators in 1996 of 1.1 MW. Some studies have been done on the spectral components of waves and their effect on the overall energy content, Yagci (2009). The extractable power available goes as the following formula:

$$
\mathrm{P}=(0.55 \mathrm{~h} 2 \mathrm{z})
$$

Where $\mathrm{P}$ is in $\mathrm{kW}$ per meter length of the wave crest. Where $h=$ average of one-third of the highest waves in meter $\mathrm{z}=$ zero crossing periods in seconds. That means a significant wave height of 4 meters, with a zero crossing period of five seconds, will have the wave power of 44 $\mathrm{kW}$ per meter length of the wave crest. Along the Indian coast of approximately $7500 \mathrm{Km}$, the average wave energy is around 5 to $10 \mathrm{~kW} / \mathrm{m}$. India has a total potential around 40,000 MW. At $15 \%$ utilization, this would mean an output of approximately $6000 \mathrm{MW}$.

\subsection{Available Technologies}

Energy can be extracted from the water-air interface of the ocean by wind, surface waves, and currents below the surface. Wind energy is mainly extracted on land, with permanent structures holding rotating blades measuring 100 meters or more. However, the same amount of energy can be extracted from water flows with considerable smaller diameter turbine blades.

The Japan Research and Development Corporation developed wave-powered devices after a study in 1965 , resulting in wave-powered generators and wave-powered light buoys, wavepowerlab (2016). Thorpe (1999) also mentions the pioneering work done by the Japanese in developing self-powered buoys. A wind-wave combination is reported in Korea, Thorpe (1999).

\subsection{Indian Ocean Networks}

In the Indian Ocean, the Indian Meteorological Department (IMD) and other networks provide real-time seismic data. Indian Ocean earthquakes larger than Magnitude 6 can be detected within 20 minutes. The main advance warning method for tsunami detection is by Deep Ocean Bottom Pressure Recorders, (BPRs). In the Bay of Bengal, NIOT, (The National Institute of Ocean Technology), has installed 4 BPRs, with 2 BPRs in the Arabian Sea, Incois (2016). Thirty Tide Gauges to monitor the progress of tsunami waves were placed by the NIOT and Survey of India (SOI). The Integrated Coastal and Marine Area Management (ICMAM), has validated the Tsunami Model for five historical earthquakes and inundations. Another study suggests that high concentrations of mangroves help protect the shoreline from wave action, [acm.org]. In Indonesia, the UN Information Management Service (UNIMS) worked with local agencies for planning and recovery activities, Harris (2007). Tidal and wave energy development has been attempted in Bay of Bengal and Vizingam, Ravindran (1995). The economics of the project will determine if the investments are worthwhile in the long run.

The INCOIS Centre, (Indian National Centre for
Ocean Information Services) operates 24 by 7 , and satellite data is received from six ocean buoys-equipped with water pressure sensors. Six back-up buoys should also now be ready. Two faults in the Indian Ocean can cause a tsunami and the Bay of Bengal, are potentially hazardous, Alam (2012)

\section{Equations}

Takao and Setoguchi (2012) have given an in-depth analysis of air turbines including Wells, Impulse and Radial Turbines for energy conversion. Since conditions of irregular flow are present, the usual steady flow analyses may not give accurate estimates. Under wave conditions, the equation used is

$$
\mathrm{Pin}=0.5 * \mathrm{H}_{1 / 3}^{2} * \mathrm{~T}^{1 / 3} * \mathrm{~W}
$$

With $\mathrm{H} 1 / 3$ and $\mathrm{T} 1 / 3$ being the significant wave height and period at the site, with $\mathrm{W}$ the chamber width.

They conclude that the running characteristics of the impulse type turbine are superior to those of the Wells type. A twin impulse type with a capability of $50 \%$ conversion in the OWC configuration is suggested (Jayashankar, 2009).

The alternative use of linear motion as in an OWC has been analyzed by Polinder (2004). The maximum extraction is possible at resonance with the wave period. The energy extracted is found to be

$$
\mathrm{Tw} \mathrm{Fw}_{\max }^{2} /(8 \beta)_{\mathrm{h}}
$$

Where

$\mathrm{FW}=$ wave diffraction force of the floater

$\beta \mathrm{h}$ hydrodynamic damping force of the floater

Tw wave period

From theoretical considerations, the power of a wave is expressed as

$$
\begin{gathered}
\mathrm{Pga}^{2} \mathrm{f} \mathrm{W} / \mathrm{m} \\
\text { With } \mathrm{P}=\mathrm{E} / \mathrm{t} \text { where } \mathrm{E}=0.5 \mathrm{Da}^{2} \lambda \mathrm{Wg} \mathrm{J}
\end{gathered}
$$

With amplitude a, g being gravitational constant, $W$ width, and time.

The problem of interfacing the output with the grid depends on whether a VSI or CSI is used (voltage source inverter or Current source inverter). An annual yield of $8.55 \mathrm{GWh}$ is calculated for Portugal based on the wave amplitude and period characteristics. The OWC coupled with a conventional turbine requires one-way flow which is usually provided by installing a valve system which blocks the backward flow of air. The non-return valve artifice can be dispensed with when Self Rectifying air turbines are used, Takao (2012).

\subsection{Potential for Incorporating Wave and Tidal Energy Generators in Early Warning Buoy Systems}

Although higher wave heights exist at higher and lower latitudes, good wave potentials exist around the Indian coast. Potential sites in India have been identified as Gulfs of Kutch and Cambay in Gujarat with maximum tides in the range of $8 \mathrm{~m}$ and $11 \mathrm{~m}$ and average tidal range of $5.23 \mathrm{~m}$ and $6.77 \mathrm{~m}$ respectively, Khan (2009). Power 
generation potentials are $7000 \mathrm{MW}$ and $1200 \mathrm{MW}$. At Durgaduani creek in the Sundarbans, a potential of 100 MW with an average and maximum tidal range of $2.97 \mathrm{~m}$ and $5 \mathrm{~m}$ has been identified. In Belladonna creek, a mean tidal range of $3.6 \mathrm{~m}$ is estimated. All these regions are in gulf and inlet areas which act as natural funnels for the gathering of wave energy. Global maps of wave heights illustrate the typical wave distributions as being highest above and below 40 degrees latitude. As early as the 1960's, Japan introduced a program for self-powered buoys, (Takao, 2012). As such many buoys in the Indian Ocean network linked by online telemetry could also be converted to self-power with excess sent to a grid.

Other locations like Norway, China, Scotland, Australia have experimented with generators, while several National Programs have also been initiated like the European and Japanese wave energy efforts, Thorpe (1999).

\subsection{Potential for Harvesting Wave Energy}

Salter (2002) suggests energy storage coupled with hydraulic machines and improvements in the design of the turbines used to extract power from such erratic flows. Hydraulic collectors of choice are in the form of pressure of potential energy involving a height of liquid. In this way, the fluctuating current obtained from electrical generators could be transformed to a steady voltage and thus rectified.

Estimates by Bedard (2005) were that hydroelectric potential was of the order of $10 \%$ of the total incident offshore wave energy, with a cost ranging from 10cents per $\mathrm{kWh}$ to 30 cents per $\mathrm{KWh}$. In Rupee terms, this translates to approximately $5 \mathrm{Rs}$ to $20 \mathrm{Rs}$ per KWh. These figures compare favorably with the estimates given in this paper for the Bengal plant, rate of interest $10-15 \%$ over 20-25 years.

A survey done in Pakistan (Leghari et al., 2014) for the delta region of the Indus River indicated a network of six turbines of total $5000 \mathrm{KW}$ with a total capital cost of $\$ 2376$ per KW. After applying a discount rate of $10 \%$ for 30 years, the cost per $\mathrm{kWh}$ is in the range $11-15$ cents/kWh, depending on the discount rate (from $10 \%$ to $15 \%)$. Estimates for India have also been given as 7000MW to 12000 MW by Khan (2009).

According to the EPRI Report (Bedard, 2015), wave energy would cost from 11 to $39 \mathrm{c} / \mathrm{KWh}$.

\subsection{Mechanisms for Extraction}

The use of energy transfer from surface waves to a carpet on the floor has been studied in view of the fact that muddy sea floors can attenuate surface turbulence, Alam (2012). A further advantage of the carpet method lies in the fact that multidirectional and broadband wave energy can be extracted, Lehmann (2013). Significant surface energy may be extractable using an artificial floor carpet in this manner. A review of current understanding of tidal energy from stream power generation was given, Bedard (2005). Around the same time, reviews were done, estimating tidal electric power generation and giving the current state of the art and its status, by Benelghali (2007), and Blumden (2007). Recently, Raja (2015) has given specific application to Malaysia, using a Utility function. Another recent study has evaluated the generation of power from ocean-based generators regarding matching it to electric grid systems using a network and impedance theory, Safayet (2015).

Extraction of energy from ocean currents thus can be done in one of several ways: Tidal stream, Barrage system, Surface wave and Floor carpet.

Subdivision of the collectors can also be done into sea-based or shore-based devices. An example of the seabased device would be the Salter's Duck. Another such device is the Clam which produces energy from ocean swells rising and falling. Shore-based systems, on the other hand, are in contact with the shore, and mostly depend on OWC's (Oscillating water columns) which drive turbines or pressurize air to run air turbines.

Tidal currents which are essentially off shore currents can be harnessed by locating barrages or fences of collecting turbines which would depend on the velocity of the stream. If the current can be funneled into an estuary, the potential of harnessing energy rises. Apart from the La Rance barrage in Brittany France, one in the Bay of Fundy, Kislaya Guba in the former USSR and Jiangxi in China, no other known estuarine barrages have been constructed to this day. This is, no doubt, attributable to the high capital cost involved. Recently it was announced that the San Bernardino Strait in the Philippines would host a 1.5MW tidal power plant, www.hydroworld (2017).

\subsection{Brief Chronology}

Since the 1970's, many technologies have been attempted; among these are:

\section{Cockerel raft}

2. Flexible bag energy converter

3. Submerged circular cylinder converter

4. Clamp wave energy converter

5. Oscillating water column converter

6. Ocean swell powered renewable energy Converter

7. Sea slot cone generator

8. TAPCHAN (Tapered Channel) collectors

\section{Dam atolls}

The first known patent for wave energy extraction is attributed to Girard of Paris in 1799, (Ross, 1995). The first major review appears to be by Salter et al. (2002), who mention that the main obstacle to using wave energy lies in the ancillary infrastructure's ability to deliver phase-locked coherent electricity of a quality acceptable to the utility grid network. This is primarily due to the erratic nature of waves which run air turbines. A recent study by Carasco et al. (2006) focuses on the same problem and suggests a network of energy sources or DER (Distributed energy network), with grid-integration of intermittent renewable energy sources and its effect on the large conventional central power station. A paper by Bahaj (2007) discusses the proposed Severn barrage in the UK and calculates a maximum of $76 \%$ of the theoretical power extractable via the tidal barrage scheme. 
Tidal stream energy around the UK was estimated at 2-7 GW compared to the $46 \mathrm{GW}$ consumed in 2005.

Amundarin et al. (2011) discuss the simulation of wave energy generators and connecting to the grid, particularly when the number of generators increases. The device studied, in particular, was the OWC (oscillating water column). Other devices are described in the paper by Benelghali et al. (2010). These can be divided into Horizontal axis systems, Vertical axis systems, Kobold turbines, Gorlov turbines. Apart from these, one could have Oscillating hydrofoils, SSG- Sea slot cone generator.

The power take-off can be by one or more of the following mechanisms; Rotary generator, Turbine, or hydraulic system, Drew (2009). These have already been analyzed by Takao (2012). The preferred energy extraction device mentioned by many is the Davis turbine. The Davis turbine has the ability to rotate unidirectionally. A further enhancement of the Davis turbine is the Gorlov Turbine, Cascio (2005). The Gorlov Turbine evolved from the wind-based Darrieus turbine with spiral blades, which has the ability to turn unidirectionally in the air. Analogously, the Gorlov turbine also spins in one direction, reducing the ancillary rectifying valve system

Many of these devices have been discussed in several papers by Mueller (2007), Falcao (2009), Benelghali (2010), Drew (2009) among others. A Variable reluctance permanent magnet motor was mentioned by Baker and Mueller (2001). They also emphasize the use of phase capacitors to maximize the extraction of power. Other problems of loading control and interfacing have been mentioned in Drew et al. (2009). Benbouzid (2015) emphasize that wave energy capture devices are necessarily large since they have to resonate with wavelength.

Recently, novel harvesting technologies for collection of underwater acoustic ultrasonic energy have been outlined by Xi et al. (2017). An efficiency of $13.1 \%$ has been reported. Improvements in efficiencies may be possible by making use of swarm and ant colony technologies in the project stage itself (Huang et al., 2015).

Mechanical artifices to extract most energy from the ebb and flow of the tide include Latching control, (Salter et al. 2002). To prevent loss of efficiency in converting linear to rotary motion one may also consider Linear Generators involving linear motors instead of rotating elements. A further means of optimizing the output is in the use of power factor capacitors.

\section{Economic Analysis}

Although wave turbines can be made much smaller than wind turbines for the same output of power, the capital cost for the ancillary equipment can be considerable. Hence in order to rationalize the choice for investment in ocean energy the payoff needs to be calculated. To do this there are several methods:

- MARR (Minimum Acceptable Rate of Return)

- NPV (Net Present Value)

- IRR (Internal Rate of Return)
- EAW (Equivalent Annual Worth).

Taking Investment for the WBREDA Sunderbans Project at 40 crore, as given in Khan (2009), and by using the annualized cost or amortized cost over the life of the project, gives an annual cost $\mathrm{A}$, with $\mathrm{P}$ being the present value, "I" the interest rate and $\mathrm{n}$ the no. of years as

$$
\mathrm{A}=\mathrm{P}^{*}\left[\mathrm{i}(1+\mathrm{i})^{\mathrm{n}}\right] /\left[(1+\mathrm{i})^{\mathrm{n}}-1\right]
$$

A more general analysis using discounted income flows and annualized capital costs is presented in an LCOE (Levelized cost of energy) where

\section{$\mathrm{LCOE}=[\operatorname{Capex}(\mathrm{t})+\mathrm{OPEX}(\mathrm{t})+\operatorname{Fuel}(\mathrm{t})] /(1+\mathrm{r})^{\wedge} \mathrm{t} / \operatorname{Egen}(\mathrm{t}) /$ $(1+\mathrm{r})^{\wedge} \mathrm{t}$}

This is the same as the present NPV of the expenditures divided by the Present NPV of the income or remuneration flow. (RSC Advances, 2014).

The EPRI method (Bedard, 2015), uses the following scheme:

Calculate annualized cost:

$$
\mathrm{COE}=[(\mathrm{TPI} * \mathrm{FCR})+(\mathrm{O} \& \mathrm{M})+(\mathrm{LO} \& \mathrm{R})] /(\mathrm{AEP})
$$

Where $\mathrm{COE}=\mathrm{Cost}$ of Energy

TPI=Total Plant Investment

FCR=Fixed Charge Rate

O\&M=Annual Operating and Maintenance Cost

LO\&R=Periodic Levelized Overhaul and Maintenance

$\mathrm{AER}=$ Annual Energy Cost at bus bar.

(Conversion \$1 =Rs 65 approx)

Magagna and Uihlein (2016), Neil et al. (2016) discuss leasing of coastal properties and effect on the output of location, and the economics of operation. Leasing different locations and combining the outputs are affected by the phase of the tidal streams. Effect of lean manufacturing and similar tools to improve efficiency and reduce waste is discussed by Davies and Van Der Merwe (2015)

\subsection{Mechanical and Energy Limitations}

In the case of the wind turbine energy extraction system, it can be shown that there is a theoretical limitation to the maximum power that can be extracted. The limit is known as the Betz criterion (Khan, 2009) and is approximately $59 \%$ (or 16/27) of the incoming energy. Hence any efficiency criterion would have to be factored by this reduction of about $3 / 5$. The criterion appears to have been neglected in all the studies surveyed so far. Since there is very little difference in the analysis for wind and water, excepting for the density and area, a similar reduction needs to be applied for any water bases system, and may further be restricted due to the nozzle and intake efficiency.

\subsection{Application to India}

At a market rate of interest $\mathrm{i}=10 \%$, for an output $3.75 \mathrm{MW}$ at $10 \mathrm{hrs}$ per day 365 days per year, the annualized rate comes to $3.75 * 10 * 365=13687.5 \mathrm{MWh}$. Supposing it 
supplies only $25 \%$ of its capacity, the actual output is $3421.9 \mathrm{MWh}$. From eqn (7). at a rate i of $10 \%$, for a capital investment of 40 crores over 25 years, the annual capitalized cost is Rs 4.4 crores. Taking an annual maintenance cost of $2 \%$ gives 80 lakhs per year. Hence total annual cost is 5.2 crores. Equating the power output at $25 \%$ capacity for 10 hours per day gives a cost of 3799 per megawatt hour or Rs 3.8 per KWh. At a rate of $15 \%$ over 20 years: annualized cost is 6 crores, with annual maintenance of 80 lakhs per year, give a total of Rs 6.8 crores for $3421.9 \mathrm{MWh}$, yielding a rate of 19.8 per KWh. These estimates may be compared to the rate in Bangalore of 5 to $6 \mathrm{Rs}$ per KWh. Appropriate adjustments can be made for inflation and incremental increases in maintenance, depreciation, and other factors. Sufficient sites exist for incorporating wave generators into the information gathering network, Gunn (2012). It is seen that sufficient potential exists in the Indian Ocean region for energy generation and can be availed of by neighboring countries. As regards the logistics, one must make sense of a large number of devices and agencies that operate data gathering units in the area. A start has been made in the disaster management regimes initiated amongst the SAARC countries, Kawata (2011), Nayak (2012). The possibility of using these sensors to track aircraft and naval vessels is also possible, [PRIS]. A rough calculation of the economics shows that the tide and wave energy production schemes can be self-sustaining at current market rates. However, actual implementation is still far off due to regional differences and bureaucracy. The effect of Technology on the cost of supplying/generating power is shown chronologically in Fig. 1.

\section{Environmental Considerations}

Carbon footprint considerations are discussed by Niles (2002) (10.1098/rsta.2002.1023), Environmental effects on the tidal marine life and other similar considerations on the effect on fisheries and are discussed for various coastal zones of the US in a workshop paper Polagye (2010). Many projects with economically attractive viability may have deleterious effects on the environment and marine life in the longer term. The tidal regions have especially fragile eco structures which are prone to chemical and temperature changes. The coral reefs which are host to many forms of aquatic life if damaged would cause cascading harm to their dependent life forms. In addition, fisheries and fishing communities would be affected along coastal zones where wave farms are located.

\section{Conclusion}

The key to generating power from ocean currents lies in the harvesting of streams situated near the coast lines. Among these are currents such as the Gulf Stream and others in the Indian Ocean. Apart from tidal currents, surface motions (bobbing) can also be harvested based on wave amplitudes and frequencies. The utilization of the density difference between air and water for augmenting energy output results in a diameter reduction of approximately 10 , as compared to wind flows. This factor can lead to enormous amounts of energy harvested from ocean currents. One may also consider the economic return on investment (ROI) as an efficiency measure, instead of mechanical efficiency, since the source of power is renewable and sustainable solar and wind energy which impacts on and is absorbed by the ocean. Moreover, once wind and solar energy get transferred to surface wave motion, the same can be transported across very long distances. The harvesting of such energy would depend on the appropriate configuration, placement, phasing of harvesters and synchronization of the output with that of the feeder grid.

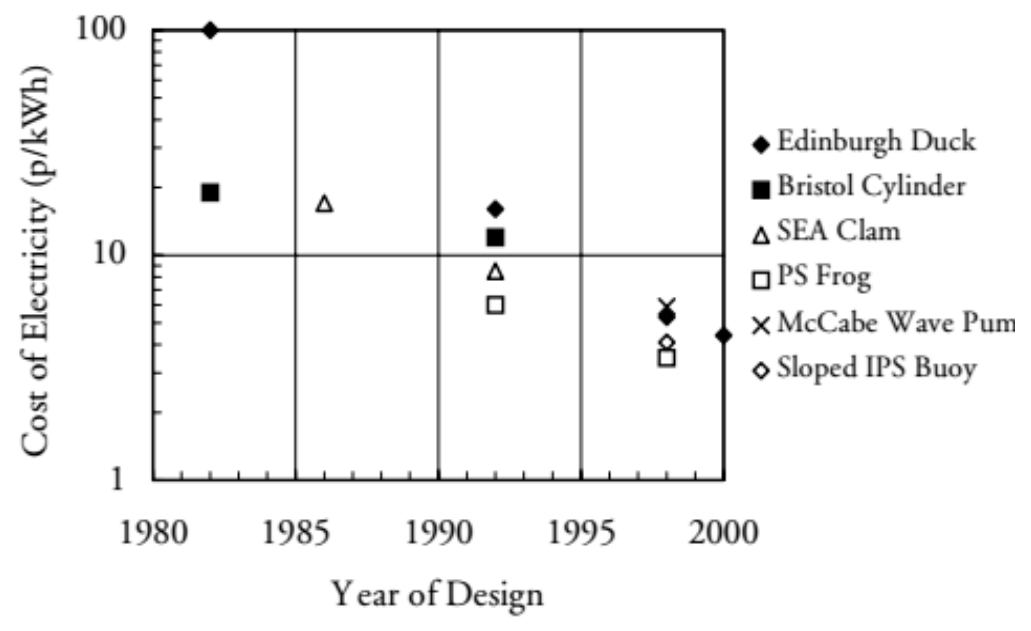

Key. ${ }^{*}$ at $8 \%$ discount rate.

Costs for year 2000 design incorporate improvements already quantified.

Fig. 1. Cost of electricity year wise (from Thorpe (1999)) 


\section{Acknowledgments}

An earlier part of this research formed the basis of a submission to the USERDA for a wave energy contest in 2015. Subsequent results were presented at the EPPM conference, Amman Jordan in Sept. 2017. The author thanks the Conference organizers and Management of Zaytoona Engineering College and Adarsha Institute of Technology for hosting the same, and the referees for a critical reading of the paper.

\section{References}

Alam, M. R. (2012). Nonlinear analysis of an actuated sea floor mounted carpet for high-performance wave energy extraction. Proc Roy Soc A, doi: 10.1098rspa 2012.0193.

Amundarai, M., Alberdi, M., and Garrido, A. J. et al. (2011). Modeling and simulation of Wave Energy Generation Plants Output Power Control. IEEE Trans on Ind. Electron, 58, 1, 105-117.

Baker, N. J. and Muleler, M. A. (2001). Direct Drive Wave Energy Converter. Rev Energy. Ren. Power Engineering, 1-7.

Bedard, R. et al. (2005). Offshore wave power feasibility Demonstration Project. 2005 E21 EPRI Global WP009-US Rev2 (Sept 22, 2005).

Benbouzid, T. H. and Benbouzid, M. (2015). An Up-toDate Technologies Review and Evaluation of Wave Energy Converters. International Review of Electrical Engineering-IREE, 10(1), 52-61.

Benelghali, S., BenBouzid, M., and Charpentier, J. F. (2007) Marine Tidal Current Electric Power Generation Technology: State of the Art and Current Status. Proc of IEEE, IEMDC07, pp. 1407-1412 (HAL-00531255).

Blumden, I. S. and Bahaj, A. S. (2007). Tidal Energy Resource Assessment for Tidal Power Generators. Proc of Inst of Mech. Engrs A, Jnl of Power and Engg, doi: 10.1243/09576509JPE332

Carrasco, J. M., Franguelo, L. G., and Bialasicwicz, J. T., et al. (2006). Power electronic system for the Grid Integration of Renewable Energy Sources-a survey. IEEE Trans on Industrial Electronics, 53, 4, 10021016.

Clement, A., McCullen, P., and Falcao, A. et al. (2002). Wave Energy Systems: Current State and Prospects. Renewable and Sustainable Energy Reviews 6 (2002) 405-431.

Davies, E. and VanDerMerwe, K. (2015). Development of a Framework for a Lean based Water and Energy Efficiency Assessment Tool. Journal of Engineering, Project and Production Management, 5(2), 98-106.

DBEDT (2002). Feasibility of Developing Wave Power as a Renewable Energy Resource for Hawaii. Department of Business, Economic Development, and Tourism. Honolulu.

Disaster Risk Management in Asia and the Pacific, Issues Paper, April 2013.

Drew, B., Plummer, A. R., and Sarpinkaya, M. N. (2009). A review of wave energy converter technology. Proc Inst Mech Engr, Part A, Jnl of Power and Energy, 223,887-902, doi: 10.1243/09576509JPE782

Gunn, K. and Stock-Williams, C. (2012). Quantifying the global wave power resource. Renew Energy, 44, 296-3
04, doi: dx.doi.org/10.1016/j.renene.2012.01.101 (acc essed Nov 2017), http://portal.acm.org/citation.cfm?id $=1452126$ (accessed Nov 2017), http://www.incois.go v.in/portal/OON.jsp (accessed Nov 2017).

Harris, P. and Shaw, D. (2007). GIS and Health Information Provision in Post-Tsunami Nanggroe Aceh Darussalam. In: Lai, P. C. and Mak, A. S. H. (eds.) GIS for Health and the Environment. Lecture Notes in Geoinformation and Cartography. Springer, Berlin, Heidelberg.

Huang, H., Huang, C., and Pei, W. (2015). Solving Multi-Resource Constrained Project Scheduling Problem using Ant Colony Optimization. Journal of Engineering, Project, and Production Management. $5(1), 2-12$.

Jayashankar, V., Anand, S., and Geetha, T. et al. (2009). A twin unidirectional impulse turbine technology for OWC based wave energy plants. Renewable energy, 34, 3, 692-698,

Kawata, Y. (2011). Downfall of Tokyo due to devastating compound disaster. Journal of Disaster Research, 6 (2), 176-184.

Khan, B. H. (2009). Nonconventional energy Resources. Tata McGraw Hill, N. Delhi.

Leghari, R. H. and Jarwar, A. H. (2014). Economic Analysis of Pilot Tidal Power Plant in Pakistan. Proc of ZEC Infrastructure, paper 1569932421.

Lehman, M., Elandt, R., Phan, H., Ghorbara, R., Shakeri, M., and Alam, M. R. (2013). An artificial sea bed carpet for multidimensional and broadband wave energy extraction: Theory and Experiment. Proc $10^{\text {th }}$ European Wave and Tidal Conf, ENTEC, 2013, 2-5, Sept 2013, Aalborg Denmark.

Lutjeharms, J. R. E., Bang, N. D., and Duncan, C. P. (1981). "Characteristics of the currents east and south of Madagascar”, Deep Sea Res. A 28(9), 879-899.

Mueller, M., Polinder, H., and Baker, N. (2007). Current and Novel Electrical Energy Technology for Wave En ergy Converters. doi: 10.1109/IEMDC.2007.383634, I E Explore.

Nayak, S. and SrinivasKumar, T. (2012). Indian Tsunami WarningSystem, www.isprs.org/proceedings/XXXVII/ congress/4_pdf/262.pdf, 2012

Niles, J. O., Brown, S., and Pretty, J. et al. (2002). Potential carbon mitigation and income in developing countries from changes in use and management of agricultural and forest lands. Philos. Trans. Roy.Soc., 360, 1621-1639:10.1098/rsta.2002.1023

Polinder, H., Damen, M. E. C., and Gardner, F. (2004). Linear PM Generator System for Wave Energy Conversion in the AWS. IEEE Trans Energy Conv, 19 ,3, 583-589.

PRIS Pacific Risk Information System, http://pcrafi.spc.int/beta (accessed Nov 2017).

Pawel, R. (2015). Utility Function and Sustainable Development-Case Study of Malaysia, Proc of IRES $7^{\text {th }}$ Intl Conf Kuala Lumpur Malaysia, 18.8.2015, (ISBN 978-93-85465-77-2).

Ravindran, M. et al. (1995). Indian Wave Energy Programme: Progress and Future Plans, Proceedings of the Second European Wave Power Conference, Lisbon, Portugal, 8-10, November 1995. 
Ross D. (1995). Power from the Waves. Oxford University Press.

RSC Electronic Supplementary Material (2014). ESI for RSC Advances 2014, c4ra0309091.

Salter, S. H., Taylor, J. R. M., and Caldwell, N. J. (2002). Power conversion Mechanism for Wave Energy, Proc Instn Mech Engrs, V.216, J. Engg. for the Marine Environment.

Safayet, A. M. (2015) Distributed Voltage Regulation and Grid Connection of Renewable Energy Sources. Dissertation, NCSU.

Szabo, L., Oprea, C., and Festilla, C. et al. (2009). Study on a Wave energy based Power System. Proc of 18th Intl Conf on Electrical Machines, Portugal, IEEE, paper 1199, 10.1109/ICELMACH.2008.4800024

Takao, M. and Setoguchi, T. (2012). Air Turbines for Wave Energy Conversion. IJRM, :10.1155/2012/717398/ (accessed Nov 2017).

Thorpe, T. W. (1999). An Overview of Wave Energy Technologies: Status, Performance, and Costs. Wave Power: Moving towards Commercial Viability, 30 November 1999, Broadway House, Westminster, London.

Tomczak, M. and Godfrey, J. S. (2003). Regional Oceanography: an Introduction. $2^{\text {nd }}$ Edn, Daya Publishing House, N Delhi, 2003.

wavepowerlab.weebly.com/blog (accessed 24 Sept 2016).

Walton, B. A. N., Hailey, J. F. M., and Hunter, P. D. (197 8). The Mauritius Wave Energy project-research resul ts and proposed outline design. Proceedings Internati onal Symposium on Wave \& Tidal Energy, Canterbury , F2, 15-38.http://www.hydroworld.com/articles/2017/ 06/us-25-million-1-5-mw-tidal-in-stream-energy-conv ersion-project-planned-in-philippines.html (accessed
Nov 2 2017).

www.ocsenergy.anl.gov. (2006). Technology white paper on Ocean Current Energy Potential on the US outer c ontinental shelf. Minerals Management Service, Rene wable Energy and Alternate Use Program, US Dept of Interior, www.uprm.edu/aret/docs/Ch_3_Ocean.pdf ( Accessed Nov 2017)

Xi, Y., Wang, J., and Yunlong, Z. et al. (2017). High efficient harvesting of underwater ultrasonic wave energy by triboelectric nanogenerator. Nano Energy, 38, 101-108.

Yagci, B. and Wegener, P. (2009). Determination of sea conditions for wave energy conversion by spectral analysis. Proceedings of the 8th European Wave and Tidal Energy Conference, Uppsala, Sweden, 2009.

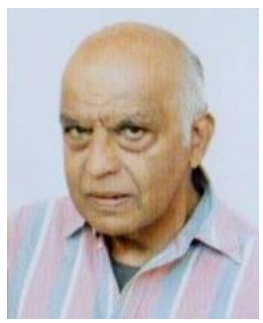

Rahul Basu is a Senior Professor of Mechanical Engineering at Adarsha Institute of Technology, VTU Bangalore. He has obtained his degrees from Caltech Pasadena, UCLA Los Angeles, and Eurotech in the USA, and was associated with various environmental projects at Los Angeles (ASCIT smog project at Caltech, Caltech MIT cross country Electric Car race 1968), biogas, solar energy and other forms of renewable energy. Recently he has participated in the USERDA contest. At EPA (RTP $\mathrm{NC}$ ), he redesigned some of the benchmark UNAMAP tape programs for desktop applications. He is a Fellow of the Indian Institution of Productions Engineers and Member of various International organizations including MRS, TMS, and Aeronautical Society of India, and Indian Institute of Metals. 